\title{
Roles of Autophagy in Regulating ER Stress-Mediated Type 2 Diabetes
}

\author{
Md Rafikul Islam ${ }^{1,2 *}$, Rashedul Alam ${ }^{3}$ and Mohammad Fazlul Kabir ${ }^{4}$ \\ ${ }^{1}$ Cardiovascular Research Institute, Yokohama City University Graduate School of Medicine, Japan \\ ${ }^{2}$ Department of Pharmacy, International Islamic University Chittagong, Bangladesh \\ ${ }^{3}$ Department of Medical Science, Chonbuk National University Medical School, South Korea \\ ${ }^{4}$ Department of Biology, Georgia State University, USA
}

*Corresponding author: Md Rafikul Islam, Cardiovascular Research Institute, Yokohama City University Graduate School of Medicine, Japan

To Cite This Article: Md Rafikul Islam, Rashedul Alam, Mohammad Fazlul Kabir. Roles of Autophagy in Regulating ER Stress-Mediated Type 2 Diabetes. Am J Biomed Sci \& Res. 2021 - 13(2). AJBSR.MS.ID.001853. DOI: 10.34297/AJBSR.2021.13.001853.

Received: 眥 June 07, 2021; Published: 㘹 June 15, 2021

\begin{abstract}
Type 2 diabetes (T2D) is a metabolic disorder closely associated with endoplasmic reticulum (ER) stress mediated $\beta$-cells loss and/or dysfunction and insulin resistance. On the other hand, ER stress and autophagy are strongly interconnected to maintain cellular homeostasis under metabolic stress and environmental cues. Therefore, co-targeting autophagy and ER stress is a promising strategy for T2D treatment.
\end{abstract}

Keywords: Diabetes; ER stress; Autophagy

Abbreviations: ER: Endoplasmic Reticulum; T2D: Type 2 diabetes; FFA: Free Fatty Acid; LC3: light chain 3; XBP1: X-Box-Binding Protein 1; TXNIP: Thioredoxin Interacting Protein

\section{Introduction}

The endoplasmic reticulum (ER) is the main site in the cell for the post-translational modification and secretion of insulin and other proteins. High blood glucose, starvation, lipid toxicity, free fatty acid (FFA), obesity, oxidative stress, insulin resistance, abnormal inflammatory response and $\mathrm{Ca} 2+$ concentration increase the burden of insulin synthesis and/or impair the insulin processing step in the ER and lead to ER stress [1-9]. Many scientific studies reported that ER stress is implicated in $\beta$-cell dysfunction, impaired insulin secretion, and insulin resistance that are considered the main reasons for the pathogenesis of T2D [7,10]. Autophagy plays an important role in regulating ER stress-mediated $\beta$-cell dysfunction and insulin resistance, although details mechanism of autophagy in diabetes remains to be elucidated. ER stress-mediated autophagy is usually activated through the ER stress-induced transcription factors such as CCAAT enhancer-binding protein (C) EBP)-homologous protein (CHOP), X-box-binding protein 1 (XBP1), or other signaling pathways such as via JNK or mTOR [11-14]. Microtubule-associated protein 1 light chain 3 (LC3), an autophagic component is reported to be activated by the ER stress-mediated phosphorylation of PERK/eIF2 $\alpha$ [15]. Autophagy suppresses ER stress-induced $\beta$-cells apoptosis through downregulation of mTORC1 and improves insulin secretion that is hampered by ER stress [16]. Indeed, $\beta$-cells Atg7 (autophagy related-7)-knockout mice show degenerated islets, impaired insulin secretion, and glucose intolerance $[17,18]$. PI3K, p85, and p85 $\beta$ are involved in unfolded protein response (UPR) gene expression through binding to X-box binding protein 1 (XBP 1) in an insulin-dependent manner $[19,20,4,21]$ demonstrated that impaired or reduced expression of functional PI3K, p85, and p85 $\beta$ in the autophagy-deficient $\beta$-cells lead to compromised UPR, increase $\beta$-cell death, and progression of diabetes in mice. Autophagy inducer (Figure 1) (rapamycin) is found to reduce forced ER stress mediated PERK, CHOP and BiP gene expression, decrease p62 level (an autophagy marker 
that accumulates in the cells if macroautophagy is suppressed), preserve the ultrastructure of ER and mitochondria, improve $\beta$ cells function and decrease $\beta$-cell death in T2D islets [22]. Rapamycin improves diabetes in diabetic Akita mice model through increasing insulin content and preventing $\beta$-cells apoptosis, while inhibition of autophagy exacerbates ER stress and diabetes [23]. It is demonstrated that autophagy-deficient $\beta$-cells are more susceptible to forced ER stress-induced cell death and proposed that autophagy plays a critical role in regulating appropriate UPR signaling and lack of autophagy hampers UPR or gene expression and increases prone to diabetes progression [4].

\section{High blood glucose, lipid toxicity, free fatty acid, starvation, obesity, oxidative stress, inflammation and $\mathrm{Ca}^{2+}$

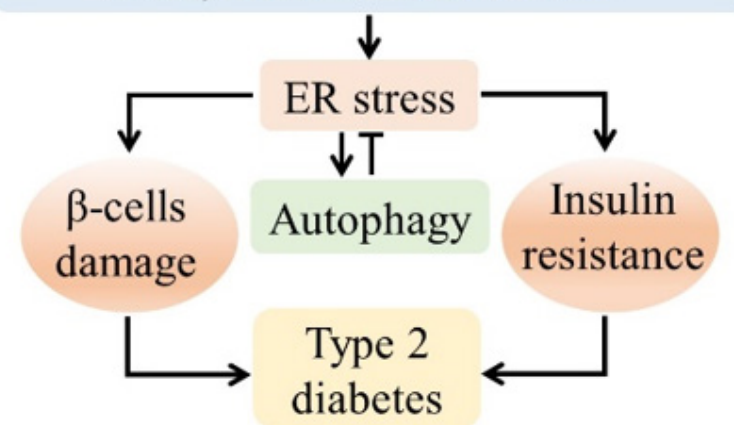

Figure 1: The relationship between ER stress, autophagy, and diabetes. Nutritional stress and environmental cues can develop type 2 diabetes through ER stress-mediated $\beta$-cells dysfunction and insulin resistance, where autophagy can play a protective role against diabetes. Although abnormal autophagy exaggerates the pathologic condition.

Several studies demonstrate that autophagy has protective roles by reducing ER stress and inflammatory cytokines (IL1 $\beta$ ) production $[5,24,25]$. Thioredoxin-interacting protein (TXNIP) is considered a potential therapeutic target for diabetes and other ER stress-mediated diseases as it is an important signaling node that links ER stress, inflammation, and autophagy [5]. TXNIP is activated by ER stress via the PERK and the IRE1 pathways, then stimulates IL1 $\beta$ production by the NLRP3 inflammasome, and increases $\beta$-cell death, whereas autophagy is observed to play important protective roles through reducing ER stress, NLRP3-dependent inflammatory cytokine production and PERK/CHOP mediated apoptosis. In contrast, autophagy is also reported to be associated with $\beta$-cells damage in T2D and might contribute to $\beta$-cells dysfunction [26]. Forced ER stress is found to trigger autophagy-mediated cell death through downregulation of the Akt/TSC/mTOR pathway [13]. Oxidative stress triggers ER stress-mediated $\beta$ cell dysfunction through impairing di-sulfide bond formation, and accumulation of misfolded proteins [6,27-29]. For instance, human diabetic islets lead to accumulating $\beta$-amyloid that is correlated with oxidative stress and apoptosis in the lack of ER stress [30,31]. In addition, autophagy is found to control hyperglycemia by reducing the oxidative stress-mediated accumulation of ubiquitinated-proteins aggregate in the $\beta$-cells [32]. ER stress under oxidative conditions suppresses insulin production, decreases $\beta$-cell mass, or even leads to $\beta$ - ubiquitin and p62, degenerate proteins, reduce insulin content, increase $\beta$-cell death, and suppress $\beta$-cell proliferation, while autophagy plays a crucial role to protect $\beta$-cell by clearing insoluble or long-lived large protein aggregates [35,4]. Recent studies demonstrate that autophagy is activated in response to lipotoxic ER stress to protect the $\beta$-cell failure [36]. Decrease in $\mathrm{Ca}^{2+}$ level in the ER leads to progress T2D through increasing the ER stress, promoting store-operated $\mathrm{Ca}^{2+}$ entry (SOCE), activating calcium-calmodulin kinase II (CaMKII), decreasing lipid removal by autophagy, and increasing insulin resistance [37]. Interestingly, Park HW et al. [38] reported that in obesity and lipotoxicity, an increase in $\mathrm{Ca}^{2+}$ concentration decreases autophagy, while $\mathrm{Ca}^{2+}$ channel blocker restores autophagic flux by enhancing autophagosome-lysosome fusion, prevents large proteins or lipid droplets accumulation, reduces inflammation, and suppresses insulin resistance. Impaired autophagy might entail the development of metabolic disorders through dysregulation of ER stress-mediated insulin resistance. For instance, autophagy is reduced in the liver of obese mice; and Atg7 (autophagy related 7) overexpression restores insulin sensitivity and decreases the expression of ER stress marker [39]. Inversely, insulin resistance inhibits Fox1-dependent expression of key autophagy genes [40]. Activation of X box-binding protein-1 (XBP1) transcription factor through ER stress-mediated phosphorylation of inositol requiring enzyme-1 $\alpha$ (IRE1 $\alpha$ ) plays a vital role in insulin resistance. ER stress by obesity/lipid injury or cytokines is found to develop insulin resistance through serine phosphorylation of insulin receptor system-1/2 (IRS-1/2) by c-Jun N-terminal protein kinase (JNK) [7,41,42].

Autophagy deficiency usually worsens the ER stress-induced inflammatory response. Yoshizaki T et al. [43] found that autophagy is decreased and inflammation is increased in adipose tissue of insulin-resistant mice and hypertrophic 3T3-L1 adipocytes; the activation of autophagy or the inhibition of ER stress (by tauroursodeoxycholic Acid) suppress inflammation through regulating phosphorylation of PERK and e-IF2 $\alpha$, expression of CHOP, and XBP-1 splicing for the expression of autophagy-related genes, such as LAMP1, LAMP2, Atg5 and inflammatory-related genes, such as MCP-1, IL-6, and IL-1 $\beta$. However, autophagy is also found to contribute to obesity/ER stress-induced insulin resistance by degradation of insulin receptors; and blocking autophagy inhibits ER stress-mediated IR degradation [44]. Autophagy may reduce insulin resistance and promote insulin signaling by reducing the overload of ER stress and facilitating ER-mediated proper IR folding and membrane targeting. In conclusion, autophagy shows 
a protective effect against diabetes through regulating ER stress, while excess or reduced autophagy would lead to failure of $\beta$-cell and hamper glucose homeostasis. Therefore, stimulating autophagy in an appropriate context could be a promising therapeutic strategy for ER stress mediated T2D.

\section{Disclosure of Potential Conflicts of Interest}

No potential conflicts of interest were disclosed.

\section{References}

1. Gomez E, Powell ML, Bevington A, Herbert TP (2008) A decrease in cellular energy status stimulates PERK-dependent eIF2 $\alpha$ phosphorylation and regulates protein synthesis in pancreatic betacells. Biochem J 410: 485-493.

2. Back SH, Scheuner D, Han J, Song B, Ribick M, et al. (2009) Translation attenuation through eIF2alpha phosphorylation prevents oxidative stress and maintains the differentiated state in beta cells. Cell Metab 10(1): 13-26.

3. Cunha DA, Hekerman P, Ladrière L, Angie Bazarra Castro, Fernanda Ortis, et al. (2008) Initiation and execution of lipotoxic ER stress in pancreatic beta-cells. J Cell Sc 121(14): 2308-2318.

4. Quan W, Lim YM, Lee MS (2012) Role of autophagy in diabetes and endoplasmic reticulum stress of pancreatic $\beta$-cells. Exp Mol Med 144(4): 81-88.

5. Liu H, Yin JJ, Cao MM, Liu GD, Su Y, et al. (2017) Endoplasmic reticulum stress induced by lipopolysaccharide is involved in the association between inflammation and autophagy in INS 1 cells. Mol Med Rep;16(5): 5787-5792.

6. Cao SS, Kaufman RJ (2014) Endoplasmic reticulum stress and oxidative stress in cell fate decision and human disease. Antioxid Redox Signal 21(3): 396-413.

7. Ozcan U, Cao Q, Yilmaz E, Lee AH, Iwakoshi NN, et al. (2004) Endoplasmic reticulum stress links obesity, insulin action, and type 2 diabetes. Science 306(5695): 457-461.

8. Ozcan L, Tabas I (2016) Calcium signaling and ER stress in insulin resistance and atherosclerosis. J Intern Med 280(5): 457-464.

9. Zhang IX, Ren J, Vadrevu S, Raghavan M, Satin LS (2020) ER stress increases store operated $\mathrm{Ca}^{2+}$ entry (SOCE) and augments basal insulin secretion in pancreatic beta cells. J Biol Chem 295(17): 5685-5700.

10. DeFronzo RA, Tobin JD, Andres R (1979) Glucose clamp technique: a method for quantifying insulin secretion and resistance. Am J Physiol 237(3): 214-23.

11. Rouschop KM, van den Beucken T, Dubois L, Niessen H, Bussink J, et al. (2010) The unfolded protein response protects human tumor cells during hypoxia through regulation of the autophagy genes MAP1LC3B and ATG5. J Clin Invest 120(1): 127-141.

12. Hetz C, Thielen P, Matus S, Nassif M, Court F, et al. (2009) XBP-1 deficiency in the nervous system protects against amyotrophic lateral sclerosis by increasing autophagy. Genes Dev 23(19): 2294-2306.

13. Qin L, Wang Z, Tao L, Wang Y (2010) ER stress negatively regulates AKT/ TSC/mTOR pathway to enhance autophagy. Autophagy 6(2): 239-247.

14. Urano F, Wang X, Bertolotti A, Zhang Y, Chung P, et al. (2000) Coupling of stress in the ER to activation of JNK protein kinases by transmembrane protein kinase IRE1. Science 287(5456): 664-666.

15. Gonzalez CD, Lee MS, Marchetti P, Pietropaolo M, Towns R, et al. (2011) The emerging role of autophagy in the pathophysiology of diabetes mellitus. Autophagy 7(1): 2-11.
16. Klionsky DJ, Abdelmohsen K, Abe A, Abedin MJ, Abeliovich H, et al (2016) Guidelines for the use and interpretation of assays for monitoring autophagy ( $3^{\text {rd }} \mathrm{Edn}$ ). Autophagy 12(1): 111-222.

17. Ebato C, Uchida T, Arakawa M, Komatsu M, Ueno T, et al. (2008) Autophagy is important in islet homeostasis and compensatory increase of beta cell mass in response to high-fat diet. Cell Metab 8(4): 325-332.

18. Jung HS, Chung KW, Won Kim J, Kim J, Komatsu M, et al. (2008) Loss of autophagy diminishes pancreatic beta cell mass and function with resultant hyperglycemia. Cell Metab 8(4): 318-324.

19. Park HW, Park H, Semple IA, Insook Jang, Seung-Hyun Ro (2014) Pharmacological correction of obesity-induced autophagy arrest using calcium channel blockers. Nat Commun 5: 4834.

20. Winnay JN, Boucher J, Mori MA, Ueki K, Kahn CR (2010) A regulatory subunit of phosphoinositide 3-kinase increases the nuclear accumulation of X-box-binding protein-1 to modulate the unfolded protein response. Nat Med 16(4): 438-445.

21. Quan W, Hur KY, Lim Y, Oh SH, Lee JC, et al. (2011) Autophagy deficiency in beta cells leads to compromised unfolded protein response and progression from obesity to diabetes in mice. Diabetologia 55(2): 392403.

22. Bugliani M, Mossuto S, Grano F, M Suleiman, L Marselli, et al. (2019) Modulation of Autophagy Influences the Function and Survival of Human Pancreatic Beta Cells Under Endoplasmic Reticulum Stress Conditions and in Type 2 Diabetes. Front Endocrinol 10:52.

23. Bachar Wikstrom E, Wikstrom JD, Ariav Y, Tirosh B, Kaiser N, et al. (2013) Stimulation of autophagy improves endoplasmic reticulum stress-induced diabetes. Diabetes 62(4): 1227-1237.

24. Oslowski CM, Hara T, O Sullivan-Murphy B, Kohsuke Kanekura, Simin $\mathrm{Lu}$, et al. (2012) Thioredoxin-interacting protein mediates ER stressinduced $\beta$ cell death through initiation of the inflammasome. Cell Metab 16(2): 265-273.

25. Ogata M, Hino S, Saito A, Morikawa K, Kondo S, et al. (2006) Autophagy is activated for cell survival after endoplasmic reticulum stress. Mol Cell Biol 26(24): 9220-9231.

26. Masini M, Bugliani M, Lupi R, del Guerra S, Boggi U, et al. (2009) Autophagy in human type 2 diabetes pancreatic beta cells. Diabetologia 52(6): 1083-1086.

27. Donath MY, Dalmas E, Sauter NS, Boni-Schnetzler M (2013) Inflammation in obesity and diabetes: islet dysfunction and therapeutic opportunity. Cell Metabolism 17(6): 860-872.

28. Eizirik DL, Miani M, Cardozo AK (2013) Signaling danger:endoplasmic reticulum stress and the unfolded protein response in pancreatic islet inflammation. Diabetologia 56(2): 234-241.

29. Montane J, Cadavez L, Novials A (2014) Stress and the inflammatory process: a major cause of pancreatic cell death in type 2 diabetes. Diabetes, Metabolic Syndrome and Obesity: Targets and Therapy 7: 2534.

30. Hull RL, Zraika S, Udayasankar J, Aston-Mourney K, Subramanian SL, et al. (2009) Amyloid formation in human IAPP transgenic mouse islets and pancreas and human pancreas, is not associated with endoplasmic reticulum stress. Diabetologia 52(6): 1102-1111.

31. Zraika S, Hull RL, Udayasankar J, Aston Mourney K, Subramanian SL, et al. (2009) Oxidative stress is induced by islet amyloid formation and timedependently mediates amyloid-induced $\beta$ cell apoptosis. Diabetologia 52: 626-635.

32. Kaniuk NA, Kiraly M, Bates H, Vranic M, Volchuk A, et al. (2007) Ubiquitinated-protein aggregates form in pancreatic beta-cells during diabetes-induced oxidative stress and are regulated by autophagy. Diabetes 56(4): 930-939. 
33. Kaneto H, Xu G, Fujii N, Kim S, Bonner-Weir S, et al. (2002) Involvement of c-Jun $\mathrm{N}$-terminal kinase in oxidative stress-mediated suppression of insulin gene expression. J Biol Chem 277(33): 30010-30018.

34. Solinas G, Naugler W, Galimi F, Lee MS, Karin M (2006) Saturated fatty acids inhibit induction of insulin gene transcription by JNK-mediated phosphorylation of insulin-receptor substrates. Proc Natl Acad Sci 103(44): 16454-16459.

35. Kirkin V, McEwan DG, Novak I, Dikic I (2009) A role for ubiquitin in selective autophagy. Mol Cell 34(3): 259-269.

36. Oh YS, Bae GD, Baek DJ, Park EY, Jun HS, etal. (2018) Fatty Acid-Induced Lipotoxicity in Pancreatic Beta-Cells During Development of Type 2 Diabetes. Front Endocrinol (Lausanne) 9:384.

37. Ali ES, Rychkov GY, Barritt GJ (2017) Metabolic Disorders and Cancer: Hepatocyte Store-Operated $\mathrm{Ca}^{2+}$ Channels in Nonalcoholic Fatty Liver Disease. Adv Exp Med Biol 993: 595-621.

38. Park SW, Zhou Y, Lee J, Lu A, Sun C, et al. (2010) The regulatory subunits of PI3K, p85alpha and p85beta, interact with XBP-1 and increase its nuclear translocation. Nat Med 16(4):429-37.
39. Yang L, Li P, Fu S, Calay ES, Hotamisligil GS (2010) Defective hepatic autophagy in obesity promotes ER stress and causes insulin resistance. Cell Metab 11(6): 467-478.

40. Liu HY, Han J, Cao SY, Hong T, Zhuo D, et al. (2009) Hepatic autophagy is suppressed in the presence of insulinresistance and hyperinsulinemia: inhibition of Fox01-dependent expression of key autophagy genes by insulin. J Biol Chem 284(45): 31484-31492.

41. Ozcan U, Yilmaz E, Ozcan L, Furuhashi M, Vaillancourt E, et al. (2006) Chemical chaperones reduce ER stress and restore glucose homeostasis in a mouse model of type 2 diabetes. Science 313(5790): 1137-1140.

42. Nakatani Y, Kaneto H, Kawamori D, Yoshiuchi K, Hatazaki M, et al. (2005) Involvement of endoplasmic reticulum stress in insulin resistance and diabetes. J Biol Chem 280(1): 847-851.

43. Yoshizaki T, Kusunoki C, Kondo M, Mako Yasuda, Shinji Kume, et al. (2012) Autophagy regulates inflammation in adipocytes. Biochem and Biophys Res Commun 417(1): 352-357.

44. Zhou L, Zhang J, Fang Q, Liu M, Liu X, et al. (2009) Autophagy-mediated insulin receptor down-regulation contributes to endoplasmic reticulum stress-induced insulin resistance. Mol Pharmacol 76(3): 596-603. 